\title{
Seasonality in fuel consumption: a case study of a gas station
}

\author{
ROSADO, JOÃO \\ MSc student, Instituto Politécnico de Portalegre (Portalegre, Portugal) \\ Correo electrónico: 16193@ipportalegre.pt \\ GUERRA, DANIEL \\ MSc student, Instituto Politécnico de Portalegre (Portalegre, Portugal) \\ Correo electrónico: 19852@ipportalegre.pt \\ FERREIRA, PAULO \\ VALORIZA - Research Center for Endogenous Resource Valorization (Portugal) \\ Instituto Politécnico de Portalegre (Portalegre, Portugal) \\ Correo electrónico: pferreira@ipportalegre.pt
}

\begin{abstract}
Oil and its derivatives are very important goods in the world, not only because of their huge use but also because the consequences of that use. The literature has plenty of works with economic analysis of the use of oil. Having available a huge amount of data, we propose an innovative approach: based on daily information of sales in a gas station since 2001 to 2018, we make a seasonality analysis of those sales. In separate analysis, using information of the both existing shifts, of the week day and of the month, we conclude that seasonality in sales is significant. This is an important information for firm managers, which could use this information to better define their strategies.
\end{abstract}

Keywords: diesel, fuel, gasoline, seasonality.

JEL classification: C10; M10; M21.

MSC2010: 62P20; 91B02; 91B84. 


\title{
Estacionalidad en el consumo de combustible: un estudio de caso de una gasolinera
}

\begin{abstract}
RESUMEN
El petróleo y sus derivados son bienes muy importantes en el mundo, no solo por su enorme uso sino también por las consecuencias de ese uso. La literatura tiene muchos trabajos con análisis económicos del uso del aceite. Teniendo disponible una gran cantidad de datos, proponemos un enfoque innovador: a partir de la información diaria de las ventas en una gasolinera desde 2001 a 2018, hacemos un análisis de estacionalidad de esas ventas. En un análisis separado, utilizando información de los dos turnos existentes, del día de la semana y del mes, concluimos que la estacionalidad en las ventas es significativa. Ésta es una información importante para los gerentes de la empresa, que podrían utilizar esta información para definir mejor sus estrategias.
\end{abstract}

Palabras clave: diesel, combustible, gasolina, estacionalidad.

Clasificación JEL: C10; M10; M21.

MSC2010: 62P20; 91B02; 91B84.

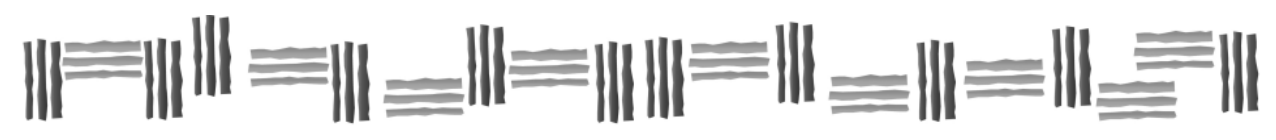




\section{Introduction.}

Without any doubt, oil is one of the most important goods in the world, because it is used as input in many industries, but also because it is used in fuel production. Over the years, with the increase of demand, there has been an increasing awareness with the dependence of fossil fuel consumption and its condition as a non-renewable resource. Moreover, problems like climatic changes, rise the necessity of studying these particular products.

We can find in the literature several works analyzing the importance of oil in the economies, namely its relationship with macroeconomic issues like economic growth (Ferderer, 1996; JiménezRodriguez \& Sanchez, 2005, among others), trade (Backus \& Crucini, 2000; Szewerniak et al., 2019) or as they affect, for example, financial markets (see, for example, Kang et al., 2015 or Narayan \& Gupta, 2015). Although, at a microeconomic level, and as a sector that moves millions, it is also relevant to study oil and derivative products, since they have direct effect on the life of consumers but also for firms.

One of the possible research areas if the way like fuel sales prices are related with the volatility of oil prices. Bacon (1986) is under the pioneers of this kind of studies. Analyzing the behavior of prices in the UK between 1982 and 1989, the author concluded that for oil price rising affect fuel prices in two weeks, but a fall in oil price just have a real adjustment in fuel prices weeks. Other studies like Bacon (1991), Borenstein et al. (1997) or Grasso and Manera (2007) corroborated this idea, being one possible justifications the fact that fuel sellers behave in an oligopolistic way, taking the opportunity of maximizing their benefits (Borenstein et al., 1997).

The analysis of elasticities involving oil prices is also a regular topic in the literatures. With this kind of analysis, it is possible to predict how consumption of fuel vary when countries' income increase as well as to analyze how the transport section is affected when a shock price occurs (Dahl, 2012). For a relatively recent review of literature about the price elasticity of this product, see the work of Hössinger et al. (2017). The work of Tirkaso and Gren (2019) extends this analysis to how elasticities have an effect on carbon taxes, in the case of Sweden, making the linkage between economy and environment.

Despite the fact that some of these works are more related with microeconomics than with macroeconomics, they do not make a firm-based analysis, which could be explained probably because of the difficulty to have available data of that kind. Although, a firm-based analysis is important for different levels and this is our proposal. In this paper, we consider the daily data from a Portuguese seller of refined oil products, namely gasoline and diesel, with different types of products.

This kind of analysis is important for several ways. Firstly, because the use of fuels for road accounts is a very important part of the oil sector (according to Dahl, 2012, it consisted of about a half of oil production consumption, in 2007). Secondly, because gasoline and diesel consumption is responsible for a high share of $\mathrm{CO}_{2}$ emissions in the OECD countries (35\%, according to IEA (2017), which made authorities to increase fuel taxes, with the consequences in sales prices. Thirdly, because the use of direct data from a given firm, could help managers of that firm to take some decisions. In fact, assessing different possibilities of seasonality, with the analysis for each of the two existing daily shifts but also with the daily and monthly analysis, we are able to answer to firm managers which is the most sold fuel, but also how consumers behave depending of the moment under analysis. Recognizing that we are using data from only one market player, it is still important the fact that the available set of data has a great richness and could be used by firm's managers to develop strategies with the objective of increase profitability in their own firm. As far as we can notice, no other work makes an analysis as such as we propose, probably because of the already identified problem in having the relevant data, making this approach innovative.

The remaining of the paper is organized as follow. Section 2 explains the data and the methodology used in this study. Section 3 presents the results. Section 4 concludes, identifying some 
possible recommendations for firm managers, the limitations of the study and also clues for further research.

\section{Data and Methodology.}

The data is from a Portuguese firm, located in Portalegre (Portugal), which sells gasoline and diesel products of different types. In this study, we will analyze the following products: gasoline with additive; diesel with additive; gasoline without plumb - 95 octanes; gasoline without plumb - 98 octanes; gasoline without plumb with additive - 95 octanes; simple diesel.

The whole set of data is composed by 6545 daily observations, with information since 30th January 2001 to 31 st December 2018. In each day, the firm works with two different shifts, the morning and the afternoon ones. For this case, a total of 13090 observations are available. Although the use of several product types, not all have the same amount of data, because different products were launched during the period under analysis. In Table 1 is possible to find a resume of the data used in this paper, which includes the following information: the first column identifies the type of product; the second column presents an abbreviation of each product, which will be used for a better identification of the product under analysis; third and fourth columns present the beginning and end dates of the analysis; the final column identifies the number of daily observations (remember that these observations are doubled, when the analysis is made considering the two daily shifts). All the variables correspond to the total daily sales in quantity of liters.

Table 1. Resume of the different products under analysis.

\begin{tabular}{|c|c|c|c|c|}
\hline Product/Variable & Abbreviation & Beginning date & End date & Daily observations \\
\hline gasoline with additive & gas add & $30 / 01 / 2001$ & $11 / 05 / 2005$ & 1563 \\
\hline diesel with additive & diesel add & $12 / 05 / 2005$ & $31 / 12 / 2018$ & 4982 \\
\hline $\begin{array}{c}\text { gasoline without plumb - } 95 \\
\text { octanes }\end{array}$ & gas95 & $30 / 01 / 2001$ & $31 / 12 / 2018$ & 6545 \\
\hline $\begin{array}{c}\text { gasoline without plumb - } 98 \\
\text { octanes }\end{array}$ & gas98 & $30 / 01 / 2001$ & $21 / 07 / 2015$ & 5286 \\
\hline $\begin{array}{l}\text { gasoline without plumb with } \\
\text { additive - } 95 \text { octanes }\end{array}$ & gas95 add & $22 / 07 / 2015$ & $31 / 12 / 2018$ & 1259 \\
\hline simple diesel & diesel & $30 / 01 / 2001$ & $31 / 12 / 2018$ & 6545 \\
\hline
\end{tabular}

Source: Own elaboration.

We apply in this study linear regression analysis, in order to identify the existence or not of seasonality in sales. For this purpose, and to ensure that the application of ordinary least squares could be applied, the first analysis about the stationarity of the sales. We use the Augmented Dickey-Fuller (ADF) test, proposed by Dickey and Fuller (1979). Considering the variable $y$ for the moment $t$, the ADF regression is given by:

$$
\Delta y_{t}=\alpha+\delta y_{t}+\rho_{1} \Delta y_{t}+\ldots+\rho_{p} \Delta y_{t-p}+\beta t+\varepsilon_{t},
$$

and the test is made under the hypotheses $\mathrm{H} 0$ : $\delta=0$ (the variable is not stationary) and $\mathrm{H} 1: \delta<0$ (the variable is stationary). In our analysis, we make all the tests considering the existence of a constant 
in the random walk, and test the variables both with and without trend. The number of lags is calculated with the AIC criteria.

Confirming the stationarity of the variables, we would apply the ordinary least squares in order to assess the existence of seasonality in sales for the different variables. The used equation is given by

$$
y_{t}=\beta_{0}+\beta_{1} d_{1}+\beta_{2} d_{2}+\cdots+\beta_{k} d_{k}+u_{t},
$$

with $y$ as each of the products/variables and $d$ each of the temporal dummies under analysis. In the case of the analysis for the shifts, $d$ is equal to 1 ; for the daily analysis $d$ is equal to 6 ; for the monthly analysis, $d$ is equal to 11 (note that we have ever to leave one temporal dummy outside the analysis, to prevent the occurrence of perfect collinearity).

\section{Results.}

Our first analysis is for the stationarity of the variables, since the stationarity is the unique way to ensure that the ordinary least squares could be used. The results are the ones presented in Table 2, where are presented for each variable the lags used in the estimation of Equation (1). As previously referred, tests were made ever considering the random walk with drift with and without trend. The results point for the stationarity of almost all variables. In the case of "diesel add", without trend the evidence is lower, while the unique non-rejection is in the case of "gas95" but just in the estimation without trend.

Table 2. Stationarity tests for the variables under study.

\begin{tabular}{ccccc}
\hline & \multicolumn{2}{c}{ Without trend } & \multicolumn{2}{c}{ With trend } \\
\hline Variable & lags & ADF statistical test & lags & ADF statistical test \\
\hline gas add & 27 & $-4.828^{* * *}$ & 27 & $-6.977^{* * *}$ \\
diesel add & 29 & $-2.726^{*}$ & 29 & $-4.144^{* * *}$ \\
gas95 & 27 & -2.483 & 27 & $-3.695^{* *}$ \\
gas98 & 30 & $-4.979^{* * *}$ & 29 & $-9.687^{* * *}$ \\
gas95 add & 27 & $-8.079^{* * *}$ & 27 & $-8.094^{* * *}$ \\
diesel & 30 & $-3.855^{* * *}$ & 30 & $-5.929^{* * *}$ \\
\hline${ }^{* * *},{ }^{* *}$ and ${ }^{*}$ mean significance, respectively, at the 1\%, 5\% and 10\% levels, based on the p-values \\
\multicolumn{4}{c}{ of MacKinnon (1994). }
\end{tabular}

Source: Own elaboration.

We started the analysis of seasonality with the regressions to allow the differentiation between shifts. The variable "morning" identifies the morning shift. As we have just two shifts, the omitted one was the "afternoon" shift. We used a trend in all the regressions (the estimation of the regressions without trend provide results that are qualitatively similar and results are available under request). The results are presented in Table 3 and show us some interesting features. Firstly, for almost all the types of fuel, the morning shift as lower sold quantities than the afternoon shift, with the exception being the sales of "diesel". This allow us to differentiate between the use of private vehicles and the use of commercial vehicles and trucks (which mostly use this type of fuel): while in this case the preference for the supply is in the morning, for the others the preference if for the afternoon. Moreover, and excepting the case of "gas95 add", all the parameters refereeing to the shift are significant, which show 
the existence of seasonality between shifts. Finally, a note for the results for the trend: in all cases but the one of "gas95 add", the trend is ever significant and mainly negative, meaning that the sales have been decreasing over time. Inclusively, the higher value of trend is for the "diesel", meaning that was it was in this product that the firm noted a high decrease of sales, which could be related to the relative proximity with the Spanish frontier and the fact that fuel is cheaper in Spain than in Portugal.

Table 3. Seasonality in different shifts.

\begin{tabular}{ccccccc}
\hline $\begin{array}{c}\text { Regression } \\
\text { parameters }\end{array}$ & gas add & diesel add & gas95 & gas98 & gas95 add & diesel \\
\hline morning & $-9.0865^{* * *}$ & $-3.0393^{* * *}$ & $-19.6869^{* * *}$ & $-3.7771^{*}$ & -2.4848 & $133.04^{* * *}$ \\
trend & $-0.0303^{* * *}$ & $0.0509^{* * *}$ & $-0.0559^{* * *}$ & $-0.0279^{* * *}$ & -0.0008 & $-0.1059^{* * *}$ \\
constant & $286.61^{* * *}$ & $-202.90^{* * *}$ & $1067.94^{* * *}$ & $242.30^{* * *}$ & $128.87^{* * *}$ & $2157.74^{* * *}$ \\
r-squared & 0.0861 & 0.3319 & 0.3684 & 0.3530 & 0.0005 & 0.2658 \\
\hline
\end{tabular}

Source: Own elaboration.

We continue our study with the analysis of seasonality in week days. As the gas station is opened in all week days, we could include in the regression six of the seven days. The results presented in Table 4 are also informative of different features. In this case, "diesel add", "gas95", "gas98" and "gas95 add" show evidence than their sales occur often in the end of the week (the first dummies in the analysis are negative, meaning than in those days sales are lower than in Sunday).

Table 4. Seasonality in different week days.

\begin{tabular}{|c|c|c|c|c|c|c|}
\hline $\begin{array}{l}\text { Regression } \\
\text { parameters }\end{array}$ & gas add & diesel add & gas95 & gas98 & gas95 add & diesel \\
\hline Monday & $18.720^{* * *}$ & -12.220 & $-72.074^{* * *}$ & $-23.295^{* * *}$ & -3.1277 & $486.19^{* * *}$ \\
\hline Tuesday & 5.1035 & -7.6865 & $-63.808^{* * *}$ & $-22.992^{* * *}$ & -6.7570 & $603.07^{* * *}$ \\
\hline Wednesday & 19.137 & -6.6235 & $-64.770^{* * *}$ & $-19.297^{* * *}$ & -4.4122 & $525.98^{* * *}$ \\
\hline Thursday & $14.056^{* *}$ & -2.1098 & $-43.356^{* * *}$ & $-13.940^{* * *}$ & 8.0014 & $562.76^{* * *}$ \\
\hline Friday & $70.571^{* * *}$ & $53.858^{* * *}$ & $90.983^{* * *}$ & $24.952^{* * *}$ & $25.970^{* * *}$ & $734.708^{* * *}$ \\
\hline Saturday & $43.077^{* * *}$ & $16.613^{* *}$ & $56.899^{* * *}$ & $20.582^{* * *}$ & $17.9109^{* * *}$ & $143.47^{* * *}$ \\
\hline trend & $-0.0303^{* * *}$ & $0.0509^{* * *}$ & $-0.0559^{* * *}$ & $-0.0279^{* * *}$ & -0.0008 & $-0.1058^{* * *}$ \\
\hline constant & $257.67^{* * *}$ & $-210.42^{* * *}$ & $1701.86^{* * *}$ & $245.27^{* * *}$ & 122.15 & $1787.44^{* * *}$ \\
\hline r-squared & 0.1416 & 0.3389 & 0.3976 & 0.3704 & 0.0326 & 0.3556 \\
\hline $\begin{array}{c}\text { F-test } \\
\text { (seasonality) }\end{array}$ & $35.01^{* * *}$ & $17.66^{* * *}$ & $108.83^{* * *}$ & $48.98^{* * *}$ & $14.05^{* * *}$ & $327.75^{* * *}$ \\
\hline
\end{tabular}

Source: Own elaboration. 
Although, individually the parameters are just significant in the cases of "gas95" and "gas98". For "gas add" and "diesel" all the parameters are positive, meaning than daily sales are higher than in Sunday, although in the case of "gas add" some of the parameters are not individually significant. Other interesting information is that the parameter of Friday is always the higher one, meaning that this is the day with higher sales. Finally, the test performed to analyse the seasonality confirms that this is a significant effect present in all the kinds of fuel.

The next analysis is for the seasonality considering as bases the month when the sale is made, with the results present in Table 5. As December is the month of reference, and as most of the parameters are negative, it means that often monthly sales are lower than in December. This is an interesting result, which is probably related with the fact that in December the demand of fuel for trips to visit family and friends in the Christmas time or eventually in holidays. In the case of "diesel", most used in transport, the high levels of sales could be related also with the increase of activity of that time of the year. Another interesting finding is that for several fuel types, the parameter of October is positive. This is related with the realization of Baja Portalegre, a very famous car competition in the city, which occurs always in October. In the case of "diesel", despite the case of October, we just find other significant parameter: August. This result is clearly related to the fact that in this month most of the firms reduce their activity due to the holidays of most of their workers. Finally, it exists evidence of seasonality in all the fuels but "gas95 add".

Table 5. Seasonality in different months.

\begin{tabular}{ccccccc}
\hline $\begin{array}{c}\text { Regression } \\
\text { parameters }\end{array}$ & gas add & diesel add & gas95 & gas98 & gas95 add & diesel \\
\hline January & $-21.935^{* * *}$ & $-46.917^{* * *}$ & $-73.224^{* * *}$ & $-13.072^{* *}$ & -6.9541 & -42.129 \\
February & $-13.829^{*}$ & $-41.022^{* * *}$ & $-69.849^{* * *}$ & $-9.5376^{*}$ & -4.2849 & -47.117 \\
March & $-29.294^{* * *}$ & $-46.408^{* * *}$ & $-70.634^{* * *}$ & $-10.843^{* *}$ & -5.9608 & -15.846 \\
April & $-25.492^{* * *}$ & $-38.842^{* * *}$ & $-56.385^{* * *}$ & -2.3318 & -1.7419 & -24.628 \\
May & $-18.362^{* *}$ & $-26.082^{* * *}$ & $-53.170^{* * *}$ & 0.7280 & -3.6928 & -11.590 \\
June & -8.3187 & -10.676 & $-46.945^{* * *}$ & 4.5773 & -0.1340 & -2.0142 \\
July & $-32.259^{* * *}$ & -1.3340 & $-49.651^{* * *}$ & 0.8914 & $-10.548^{*}$ & -18.163 \\
August & $-48.871^{* * *}$ & $16.851^{*}$ & $-42.403^{* * *}$ & 3.8838 & -7.2652 & $-75.582^{* * *}$ \\
September & $-26.362^{* * *}$ & -9.704 & $-39.343^{* * *}$ & -3.6138 & -1.4200 & 34.536 \\
October & $-16.520^{* *}$ & $27.626^{* * *}$ & -14.628 & $47.692^{* * *}$ & 9.0669 & $103.98^{* * *}$ \\
November & $-20.146^{* *}$ & $-18.223^{*}$ & $-35.345^{* * *}$ & 2.0243 & 2.8116 & 27.115 \\
trend & $-0.0307^{* * *}$ & $0.0509^{* * *}$ & $-0.0561^{* * *}$ & $-0.0279^{* * *}$ & -0.0012 & $-0.1062^{* * *}$ \\
constant & $304.57^{* * *}$ & $-188.63^{* * *}$ & $1104.79^{* * *}$ & $238.76^{* * *}$ & $134.16^{* * *}$ & $2231.81^{* * *}$ \\
r-squared & 0.0990 & 0.3404 & 0.3711 & 0.3636 & 0.1557 & 0.2619 \\
F-test & $4.79^{* * *}$ & $11.76^{* * *}$ & $6.67^{* * *}$ & $16.20^{* * *}$ & 1.51 & $5.11^{* * *}$ \\
(seasonality) & & & & & \\
\hline
\end{tabular}

***, ** and ${ }^{*}$ mean significance, respectively, at the $1 \%, 5 \%$ and $10 \%$ levels. The "F-test (seasonality)" line is the statistical value of the seasonality test, i.e., assessing jointly the significance of all the temporal dummy variables.

Source: Own elaboration. 


\section{Discussion and concluding remarks.}

In this paper, we propose to make a firm-based analysis to the sales of a gas station seeded in Portalegre, Portugal. In particular, we analyze the existence of seasonality in sales depending on three different points of view: shifts, week days and months. The results are very interesting and point to the existence of seasonality in all the cases, but with different features.

When we compare the morning shift with the afternoon one, most of the fuels show significance of higher sales in the afternoon than in the morning. With the opposite results appears the sales of "diesel", which is explained by the fact that this kind of fuel is hugely used professionally, and in this case the supply of fuel is made in the morning.

The analysis of week days, allow us to identify that in several cases, the sales are higher in the end of the season than in the beginning. Once again, the "diesel" shows a different behaviour, namely the fact that the parameters have all positive signal. Moreover, in all the day with higher sales is Friday.

Finally, when analyzing the seasonality considering monthly information, December and October seem to be the best months of sales: in the case of December because of trips associated to Christmas (in the case of "diesel" because it is a time of more general sales, which imply higher transportation needs); in the case of October, because of the Baja event.

This kind of information is very interesting for firm managers and could be used in different ways aiming the increase of profitability in the specific business. Note that the existing of seasonality makes sales more predictable and, in this case, this could be used, for example, in pricing. If in the case of shifts it is hard to make changes, it is possible for decision makers to manage the price according with the demand: knowing than demand is higher, it makes possible to put higher prices. Contrarily, if managers think that the demand is lower, they could make promotions to enhance the sales.

Despite of the used approach, it is important to identify some of the limitations of this study. Firstly, as we note previously, we are using data from just one firm, which is not necessarily the relevant market. Secondly, using just data from one firm does not able us to cross information with competitors, which could also be relevant in defining the sales of this firm. Thirdly, and despite the main sales of the firm are fuels, other products are sold (for example, some food and beverages). Although, we believe that these products do not have a relevant share in sales. Finally, we could not introduce in the analysis issues like the increase of electric cars, which could also be affecting fuel sales. Independently of these limitations, we believe that the used sample size gives us some confidence on the results. Moreover, the kind of information we use is hard to obtain for other competitors.

In the future, we want to increase the information of our dataset, including for example the daily prices of the fuels. In this case, we will be able to estimate demand curves and to obtain elasticities for each kind of fuel.

\section{Acknowledgment}

Paulo Ferreira acknowledges the financial support of Fundação para a Ciência e a Tecnologia (grants UIDB/05064/2020 and UIDB/04007/2020). 


\section{References}

Backus, D., \& Crucini, M. (2000). Oil Prices and the terms of trade. Journal of International Economics, 50(1), 185-213. https://doi.org/10.1016/S0022-1996(98)00064-6.

Bacon, R. (1986). UK gasoline prices: How fast are changes in crude prices transmited to the pump? Oxford Institute for Energy Studies EE2.

Bacon, R. (1991). Rockets and Feathers: The asymmetric speed of adjustment of UK retail gasoline prices to cost changes. Energy Economics, 13, 211-218. https://doi.org/10.1016/01409883(91)90022-R.

Borenstein, S., Cameron, A., \& Gilbert, R. (1997). Do gasoline prices respond asymmetrically to crude oil price changes? The Quarterly Journal of Economics, 112, 305-339. https://doi.org/10.1162/003355397555118.

Dahl, C. (2012). Measuring global gasoline and diesel price and income elasticities. Energy Policy, 41, 2-13. https://doi.org/10.1016/j.enpol.2010.11.055.

Dickey, D., \& Fuller, W. (1979). Distribution of the estimators for autoregressive time series with a unit root. Journal of the American Statistical Association, 74, 427-431. https://doi.org/10.2307/2286348.

Ferderer, J. (1996). Oil price volatility and the macroeconomy. Journal of Macroeconomics, 18(1), 126. https://doi.org/10.1016/S0164-0704(9. 6)80001-2.

Grasso, M., \& Manera, M. (2007). Asymmetric error correction models for the oil-gasoline price relationship. Energy Policy, 35(1), 156-177. https://doi.org/10.1016/j.enpol.2005.10.016.

Hössinger, R., Link, C., Sonntag, A., \& Stark, J. (2017). Estimating the price elasticity of fuel demand with stated preferences derived from a situational approach. Transportation Research Part A: Policy and Practice, 103, 154-171. https://doi.org/10.1016/j.tra.2017.06.001.

IEA (International Energy Agency) (2017). CO2 emissions from fuel combustion: overview. International Energy Agency.

Jiménez-Rodriguez, R., \& Sánchez, M. (2005). Oil price shocks and real GDP growth: empirical evidence for some OECD countries. Applied Economics, 37(2), 201-228. https://doi.org/10.1080/0003684042000281561.

Kang, W., Ratti, R., \& Yoon, K. (2015). The impact of oil price shocks on the stock market return and volatility relationship. Journal of International Financial Markets, Institutions and Money, 34, 4154. https://doi.org/10.1016/j.intfin.2014.11.002.

MacKinnon, J. (1994). Approximate asymptotic distribution functions for unit-root and cointegration tests. Journal of Business and Economic Statistics, 12, 167-176. https://doi.org/10.2307/1391481.

Narayan, P., \& Gupta, R. (2015). Has oil price predicted stock returns for over a century? Energy Economics, 48, 18-23. https://doi.org/10.1016/j.eneco.2014.11.018.

Szewerniak, W., Xu, Y., \& Dall'erba, S. (2019). The effects of diesel price on regional trade in the USA. Journal of Economic Geography, 19(5), 1099-1118. https://doi.org/10.1093/jeg/lby052. 
Tirkaso, W., \& Gren, I. (2019). National gasoline and diesel demand elasticities and regional effects of carbon taxes in Sweden. Swedish University of Agriculture Sciences Working paper 02/2019. DOI:10.13140/RG.2.2.24915.84003. 